\title{
Dimensi Metrik Ketetanggaan Lokal Graf Hasil Operasi $k$-Comb
}

\author{
Fryda Arum Pratama ${ }^{1}$, Liliek Susilowati ${ }^{2, *}$, Moh. Imam Utoyo ${ }^{3}$ \\ ${ }^{1,2,3}$ Departemen Matematika, Fakultas Sains dan Teknologi, Kampus C \\ Universitas Airlangga, Jl. Mulyorejo, Surabaya \\ *Corresponding author: liliek-s@ fst.unair.ac.id
}

\begin{abstract}
Research on the local adjacency metric dimension has not been found in all operations of the graph, one of them is comb product graph. The purpose of this research was to determine the local adjacency metric dimension of k-comb product graph and level k comb product graph between any connected graph $\mathrm{G}$ and $\mathrm{H}$. In this research graph $\mathrm{G}$ and graph $\mathrm{H}$ such as cycle graph, complete graph, path graph, and star graph. K-comb product graph between any graph $\mathrm{G}$ and $\mathrm{H}$ denoted by $\mathrm{Go}_{\mathbf{k}} \mathrm{H}$. While level k comb product graph between any graph $\mathrm{G}$ and $\mathrm{H}$ denoted by $\mathrm{Go}^{\mathbf{k}} \mathrm{H}$.

In this research, local adjacency metric dimension of $\mathrm{Go}_{\mathbf{k}} \mathrm{S}_{\mathrm{m}}$ graph only dependent to multiplication of the cardinality of $\mathrm{V}(\mathrm{G})$ and many of $\mathrm{k}$ value, while $\mathrm{G} \mathbf{o}_{\mathbf{k}} \mathrm{K}_{\mathrm{m}}$ graph and $\mathrm{G} \mathbf{o}_{\mathbf{k}} \mathrm{C}_{\mathrm{m}}$ graph is dependent to dominating number of $G$ and multiplication of the cardinality of $V(G)$, many of $k$ value, and local adjacency metric dimension of $\mathrm{K}_{\mathrm{m}}$ graph or $\mathrm{C}_{\mathrm{m}}$ graph. And then, local adjacency metric dimension of $G \mathbf{o}_{\mathbf{k}} S_{m}$ graph only dependent to the cardinality of $V\left(G \mathbf{o}^{\mathrm{k}-1} \mathrm{~S}_{\mathrm{m}}\right)$, while $G \mathbf{o}^{\mathbf{k}} \mathrm{K}_{\mathrm{m}}$ graph and $\mathrm{G} \mathbf{o}^{\mathrm{k}} \mathrm{C}_{\mathrm{m}}$ graph is dependent to dominating number of $\mathrm{G}$ and multiplication of the local adjacency metric dimension of $K_{m}$ graph or $C_{m}$ graph with cardinality of $V\left(G \mathbf{o}^{k-1} K_{m}\right)$ or $V\left(G \mathbf{o}^{k-1} C_{m}\right)$.
\end{abstract}

Keywords: Local Adjacency Metric Dimension, k-Comb Product Graph, Level k Comb Product Graph, Complete Graph, Path Graph, Cycle Graph, and Star Graph.

\section{Pendahuluan}

Teori graf merupakan salah satu cabang ilmu matematika yang dapat digunakan sebagai penyelesaian masalah apabila permasalah tersebut disajikan dalam bentuk titik (vertex) dan sisi (edge). Salah satu kajian yang terus berkembang dalam teori graf adalah dimensi metrik. Konsep dimensi metrik dikenalkan oleh Frank Harary pada tahun 1976. Penelitian dimensi metrik dilakukan salah satunya oleh Iswadi dkk [1] pada graf hasil operasi korona. Pada tahun 2010, Okamoto dkk [2] memodifikasi himpunan pembeda pada dimensi metrik menjadi himpunan pembeda lokal. Himpunan pembeda pada dimensi metrik juga dimodifikasi oleh Jannesari dan Omoomi [3] menjadi himpunan pembeda ketetanggaan. Selanjutnya, Rodriguez dkk [4] memunculkan definisi himpunan pembeda ketetanggaan lokal dengan menggabungkan definisi himpunan pembeda lokal dan himpunan pembeda ketetanggaan. 
Penelitian dilanjutkan oleh Rodriguez dan Fernau [5] meneliti dimensi metrik ketetanggaan dan dimensi metrik ketetanggaan lokal pada graf operasi korona dan graf hasil kali kuat. Pada penelitian tersebut juga dijelaskan dimensi metrik ketetanggaan lokal dari graf bintang, graf lintasan, graf siklus, dan graf lengkap. Selanjutnya pada tahun yang sama penelitian dilanjutkan oleh Susilowati, dkk [6] tentang kekomutatifan operasi korona dan graf hasil operasi kali comb secara dimensi metrik dan secara dimensi metrik lokal. Dalam penelitian tersebut diperkenalkan definisi operasi $k$-comb untuk sebarang graf $G$ dan $H$. Selain itu, dijelaskan pula dimensi metrik dan dimensi metrik lokal dari graf operasi $k$-comb. Pada penelitian ini dimensi metrik ketetanggaan lokal dikembangkan pada graf operasi comb, comb tingkat $k$ dan $k$-comb yaitu.

Menurut Rodriguez dan Fernau [5], misalkan $G$ graf terhubung, himpunan titik yang bertetangga dengan titik $v$ pada graf $G$ dinotasikan sebagai $N(v)$. Himpunan $W$ adalah himpunan pembeda ketetanggan lokal (local adjacency resolving set) jika untuk setiap dua titik yang bertetangga $x, y \in V(G)-W$ terdapat $z \in W$ sedemikian hingga $|N(z) \cap\{x, y\}|=1$. Himpunan pembeda ketetanggan lokal dengan kardinalitas minimum disebut basis ketetanggan lokal (local adjacency basis) untuk graf $G$, sedangkan kardinalitas dari basis disebut dimensi metrik ketetanggan lokal yang dinotasikan dengan $\operatorname{dim}_{A l}(G)$.

\section{Dimensi Metrik Ketetanggaan Lokal Graf Hasil Operasi $\boldsymbol{k}$-Comb}

Berikut ini disajikan sifat himpunan pembeda ketetanggaan local pada graf siklus dan graf lintasan.

Lema 2.1 Misalkan $G$ merupakan graf $P_{n}$ atau graf $C_{n}, W^{\prime} \subseteq V(G)$, dan $W^{\prime}=\left\{v_{n_{i}} \mid i=\right.$ $1,2, \ldots, k$ dengan $\left.n_{i}<n_{i+1}\right\}$. Jika terdapat $v_{n_{i}}, v_{n_{i+1}} \in W^{\prime}$ sehingga $l\left(v_{n_{j}}-\right.$ $\left.v_{n_{j+1}}\right)>4$ maka $W^{\prime}$ bukan himpunan pembeda ketetanggaan lokal.

Bukti. Misalkan $G$ merupakan graf $P_{n}$ atau graf $C_{n}$ dengan $V(G)=\left\{v_{1}, v_{2}, \ldots, v_{n}\right\}, W^{\prime} \subseteq$ $V(G)$ dan $W^{\prime}=\left\{v_{n_{i}} \mid i=1,2, \ldots, k\right.$ dengan $\left.n_{i}<n_{i+1}\right\}$. Jika terdapat $v_{n_{i}}, v_{n_{i+1}} \in W^{\prime}$ dengan $l\left(v_{n_{i}}-v_{n_{i+1}}\right)>4$, berdasarkan himpunan titik pada graf $G$ diperoleh bahwa $v_{\left(n_{i}\right)+j} \in V(G)-W^{\prime}$ dengan $j \in\{1,2, \ldots, t\}, t \geq 5$ sehingga terdapat $v_{\left(n_{i}\right)+2}, v_{\left(n_{i}\right)+3} \in$ $V(G)-W^{\prime}$.

Untuk $G$ merupakan graf $P_{n}$. Diambil sebarang $v \in W^{\prime}$ maka terdapat tiga kemungkinan yaitu:

(i) Jika $v=v_{n_{i}}$, maka $N(v)=\left\{\begin{array}{c}\left\{v_{\left(n_{i}\right)+1}\right\} \text {, untuk } n_{i}=1 \\ \left\{v_{\left(n_{i}\right)+1}, v_{\left(n_{i}\right)-1}\right\} \text {, untuk } n_{i} \text { yang lain }\end{array}\right.$ sehingga $\left|\left\{v_{\left(n_{i}\right)+2}, v_{\left(n_{i}\right)+3}\right\} \cap N(v)\right|=0 \neq 1$ 
(ii) Jika $v=v_{n_{i+1}}$, maka $N(v)=\left\{\begin{array}{c}\left\{v_{\left(n_{i+1}\right)-1}\right\} \text {, untuk } n_{i+1}=n \\ \left\{v_{\left(n_{i+1}\right)+1}, v_{\left(n_{i+1}\right)-1}\right\} \text {, untuk } n_{i+1} \text { yang lain }\end{array}\right.$ sehingga $\left|\left\{v_{\left(n_{i}\right)+2}, v_{\left(n_{i}\right)+3}\right\} \cap N(v)\right|=0 \neq 1$

(iii) Jika $v \neq v_{n_{i}}$ dan $v \neq v_{n_{i+1}}$ maka terdapat $n_{k}<n_{i}$ sehingga $v=v_{n_{k}}$ atau terdapat $n_{t}>n_{i+1}$ sehingga $v=v_{n_{t}}$. Oleh karena itu, $v_{\left(n_{i}\right)+2}, v_{\left(n_{i}\right)+3} \notin N(v)$ sehingga $\left|\left\{v_{\left(n_{i}\right)+2}, v_{\left(n_{i}\right)+3}\right\} \cap N(v)\right|=0 \neq 1$.

Untuk $G$ merupakan graf $C_{n}$. Diambil sebarang $z \in W^{\prime}$ maka terdapat tiga kemungkinan yaitu:

(i) Jika $z=v_{n_{i}}$, maka $N(z)=\left\{\begin{array}{c}\left\{v_{\left(n_{i}\right)+1}, v_{n}\right\}, \text { untuk } n_{i}=1 \\ \left\{v_{\left(n_{i}\right)+1}, v_{\left(n_{i}\right)-1}\right\} \text {, untuk } n_{i} \text { yang lain }\end{array}\right.$ sehingga $\left|\left\{v_{\left(n_{i}\right)+2}, v_{\left(n_{i}\right)+3}\right\} \cap N(z)\right|=0 \neq 1$

(ii) Jika $z=v_{n_{i+1}}$, maka $N(z)=\left\{\begin{array}{c}\left\{v_{1}, v_{\left(n_{i+1}\right)-1}\right\} \text {, untuk } n_{i+1}=n \\ \left\{v_{\left(n_{i+1}\right)+1}, v_{\left(n_{i+1}\right)-1}\right\} \text {, untuk } n_{i+1} \text { yang lain }\end{array}\right.$ sehingga $\left|\left\{v_{\left(n_{i}\right)+2}, v_{\left(n_{i}\right)+3}\right\} \cap N(z)\right|=0 \neq 1$

(iii) Jika $z \neq v_{n_{i}}$ dan $z \neq v_{n_{i+1}}$ maka terdapat $n_{k}<n_{i}$ sehingga $z=v_{n_{k}}$ atau terdapat $n_{t}>n_{i+1}$ sehingga $z=v_{n_{t}}$. Oleh karena itu, $v_{\left(n_{i}\right)+2}, v_{\left(n_{i}\right)+3} \notin N(z)$ sehingga $\left|\left\{v_{\left(n_{i}\right)+2}, v_{\left(n_{i}\right)+3}\right\} \cap N(z)\right|=0 \neq 1$.

Berdasarkan uraian di atas diperoleh bahwa $W^{\prime}$ bukan merupakan himpunan pembeda ketetanggaan lokal.

Pada penelitian ini dilengkapi pula hasil dimensi metrik ketetanggaan local dari graf $C_{n}$, graf $P_{n}$, graf $K_{n}$, dan graf $S_{n}$ yang sudah ditemukan oleh Rodriquez, hanya saja disajikan kembali dilengkapi dengan bukti analitiknya yang belum dijelaskan pada penelitian sebelumnya.

Teorema 2.2 [4]. $\operatorname{dim}_{A l}\left(P_{n}\right)=\left\lceil\frac{n-1}{4}\right\rceil$ dengan $n \geq 2$.

Bukti. Misalkan $V\left(P_{n}\right)=\left\{v_{i} \mid i=1,2, \ldots, n\right\}$ dan $E\left(P_{n}\right)=\left\{\left(v_{i}, v_{i+1}\right) \mid i=1,2, \ldots, n-1\right\}$. Terdapat lima kemungkinan nilai $n$ pada graf $P_{n}$ yaitu $n=2$ atau terdapat $m \geq 1$ sehingga $n=4 m-1, n=4 m, n=4 m+1$, atau $n=4 m+2$.

i. Jika $n=2$, dipilih $W=\left\{v_{2}\right\}$. Karena tidak terdapat pasangan titik yang bertetangga $x, y \in V\left(P_{n}\right)-W$, maka $W$ merupakan himpunan pembeda ketetanggaan lokal dengan $|W|=\left\lceil\frac{2-1}{4}\right\rceil$. 
ii. Jika $n=(4 m+2), m \in \mathbb{N}$. Misalkan $W=\left\{v_{3+4(k-1)}: k<\left\lceil\frac{n-1}{4}\right\rceil, k \in \mathbb{N}\right\} \cup\left\{v_{n}\right\}$ sehingga $|W|=\left[\frac{n-1}{4}\right]$. Diambil sebarang $v_{i} \in W$ pada graf $P_{n}$ maka $v_{i}=v_{3+4(k-1)}$ dengan $k<\left\lceil\frac{n-1}{4}\right\rceil, k \in \mathbb{N}$ atau $v_{i}=v_{n}$, sehingga

$N\left(v_{i}\right)=\left\{\begin{array}{c}\left\{v_{n-1}\right\}, \text { untuk } v_{i}=v_{n} \\ \left\{v_{3+4(k-1)+1}, v_{3+4(k-1)-1}\right\}, \text { untuk } v_{i}=v_{3+4(k-1)}\end{array}\right.$

Diambil sebarang titik bertetangga $x, y \in V\left(P_{n}\right)-W$, terdapat dua kemungkinan titik bertetangga yaitu $x=v_{3+4(k-1)-2}, y=v_{3+4(k-1)-1}$ dan $x=v_{3+4(k-1)+1}, y=$ $v_{3+4(k-1)+2}$ dengan $k<\left\lceil\frac{n-1}{4}\right\rceil, k \in \mathbb{N}$. Oleh karena itu,

$\left|\left\{v_{3+4(k-1)-2}, v_{3+4(k-1)-1}\right\} \cap N\left(v_{3+4(k-1)}\right)\right|=\left|\left\{v_{3+4(k-1)-1}\right\}\right|=1$ atau

$\left|\left\{v_{3+4(k-1)+1}, v_{3+4(k-1)+2}\right\} \cap N\left(v_{3+4(k-1)}\right)\right|=\left|\left\{v_{3+4(k-1)+1}\right\}\right|=1$. Berdasarkan uraian di atas dapat disimpulkan bahwa $W$ merupakan himpunan pembeda ketetanggaan lokal dengan $|W|=\left\lceil\frac{n-1}{4}\right\rceil$.

iii. Sedangkan jika $n=4 m-1, n=4 m$, atau $n=4 m+1$. Misalkan $\quad W=$ $\left.\left\{v_{3}, v_{7}, \ldots, v_{3+4(k-1)}, \ldots, v_{[3+4}\left(\left[\frac{n-1}{4}\right]-1\right)\right]\right\}$ dengan $k$ merupakan urutan titik ke- $k$ pada $W$ dengan $k=1,2,3, \ldots,\left\lceil\frac{n-1}{4}\right\rceil$ sehingga $|W|=\left\lceil\frac{n-1}{4}\right\rceil$. Diambil sebarang $v_{i} \in W$ pada graf $P_{n}$ maka terdapat $i=3,7, \ldots, 3+4(k-1), \ldots, 3+4\left(\left\lceil\frac{n-1}{4}\right\rceil-1\right)$ sehingga diperoleh

$N\left(v_{i}\right)=\left\{\begin{array}{c}\left\{v_{n-1}\right\}, \text { untuk } v_{i}=v_{n} \\ \left\{v_{3+4(k-1)+1}, v_{3+4(k-1)-1}\right\} \text {, untuk yang lain }\end{array}\right.$

Diambil sebarang titik yang bertetangga $x, y \in V\left(P_{n}\right)-W$, maka terdapat dua kemungkinan dua titik bertetangga yaitu $x=v_{3+4(k-1)-2}, y=v_{3+4(k-1)-1}$ dan $x=$ $v_{3+4(k-1)+1}, y=v_{3+4(k-1)+2}$ dengan $k=1,2, \ldots,\left\lceil\frac{n-1}{4}\right\rceil$. Oleh karena itu:

$\left|\left\{v_{3+4(k-1)-2}, v_{3+4(k-1)-1}\right\} \cap N\left(v_{3+4(k-1)}\right)\right|=\left|\left\{v_{3+4(k-1)-1}\right\}\right|=1$ atau $\left|\left\{v_{3+4(k-1)+1}, v_{3+4(k-1)+2}\right\} \cap N\left(v_{3+4(k-1)}\right)\right|=\left|\left\{v_{3+4(k-1)+1}\right\}\right|=1$.

Berdasarkan uraian di atas $W$ merupakan himpunan pembeda ketetanggaan lokal. Selanjutnya ditunjukkan bahwa $W$ merupakan basis ketetanggaan lokal pada graf lintasan. Diambil sebarang $U \subseteq V\left(P_{n}\right)$ dengan $|U|<|W|$. Terdapat tiga kasus yaitu $n \leq$ $5,5<n \leq 9$, atau $n>9$.

(i) Untuk $n \leq 5,|U|<|W|=\left\lceil\frac{n-1}{4}\right\rceil=1$ akibatnya $U=\emptyset$. Berdasarkan Definisi himpunan pembeda ketetanggaan lokal maka $U$ bukan merupakan himpunan pembeda ketetanggaan lokal. 
(ii) Untuk $5<n \leq 9,|U|<|W|=\left\lceil\frac{n-1}{4}\right\rceil=2$ akibatnya $|U|=1$. Misalkan $U=\left\{v_{i}\right\}$. Karena $\left|V\left(P_{n}\right)-U\right| \geq 5$ maka terdapat pasangan titik bertetanga $v_{j}, v_{j+1} \in$ $V\left(P_{n}\right)-U$ dengan $d\left(v_{i}, v_{j}\right)>1$ atau $d\left(v_{i}, v_{j+1}\right)>1$ sehingga $\mid\left\{v_{j}, v_{j+1}\right\} \cap$ $N\left(v_{i}\right) \mid=0 \neq 1$. Berdasarkan Definisi himpunan pembeda ketetanggaan lokal maka $U$ bukan merupakan himpunan pembeda ketetanggaan lokal.

(iii) Untuk $n>9$, terdapat dua kemungkinan jarak antara anggota $U$ yaitu untuk setiap $v_{i}, v_{j} \in U$ dengan $i<j, d\left(v_{i}, v_{j}\right)<5$ atau terdapat $v_{i}, v_{j} \in U$ dengan $i<j$, $d\left(v_{i}, v_{j}\right) \geq 5$. Jika untuk setiap $v_{i}, v_{j} \in U$ dengan $d\left(v_{i}, v_{j}\right)<5$, maka terdapat pasangan titik bertetangga $v_{t}, v_{t+1} \in V\left(P_{n}\right)-U$ dengan $d\left(v_{j}, v_{t}\right)>1$ atau $d\left(v_{i}, v_{t+1}\right)>1$ sehingga $\left|\left\{v_{t}, v_{t+1}\right\} \cap N\left(v_{j}\right)\right|=0 \neq 1$. Berdasarkan Definisi himpunan pembeda ketetanggaan lokal $U$ bukan himpunan pembeda ketetanggaan lokal. Sebaliknya jika terdapat $v_{i}, v_{j} \in U$ dengan $i<j, d\left(v_{i}, v_{j}\right) \geq 5$, berdasarkan Lema 2.1 maka $U$ bukan himpunan pembeda ketetanggaan lokal.

Oleh karena itu $W$ merupakan basis ketetanggaan lokal dari graf $P_{n} \operatorname{dan} \operatorname{dim}_{A l}\left(P_{n}\right)=$ $\left\lceil\frac{n-1}{4}\right\rceil$

Teorema 2.3 [4]. $\operatorname{dim}_{A l}\left(C_{n}\right)=\left\lceil\frac{n}{4}\right\rceil$ dengan $n \geq 4$

Bukti. Misalkan $\quad V\left(C_{n}\right)=\left\{v_{1}, v_{2}, \ldots, v_{n-1}, v_{n}\right\}, \quad E\left(C_{n}\right)=\left\{\left(v_{i}, v_{n}\right) \cup\right.$ $\left(v_{i}, v_{i+1}\right)$, dengan $\left.i=1,2, \ldots, n-1\right\}, \quad W \in V\left(C_{n}\right), \quad$ dan $\quad W=$ $\left.\left\{v_{1}, v_{5}, \ldots, v_{4(k-1)+1}, \ldots, v_{[4}\left(\left[\frac{n}{4}\right]-1\right)+1\right]\right\}$ dengan $k$ merupakan urutan titik ke- $k$ pada $W$ dengan $k \leq\left\lceil\frac{n}{4}\right\rceil, k \in \mathbb{N}$ sehingga $|W|=\left\lceil\frac{n}{4}\right\rceil$. Diambil sebarang $v_{i} \in W$ pada graf $C_{n}$ maka terdapat $i=1,5, \ldots, 4(k-1)+1, \ldots, 4\left(\left\lceil\frac{n}{4}\right\rceil-1\right)+1$ sehingga diperoleh

$$
N\left(v_{i}\right)=\left\{\begin{array}{c}
\left\{v_{2}, v_{n}\right\}, \text { untuk } i=1 \\
\left\{v_{n-1}, v_{1}\right\}, \text { untuk } i=n \\
\left\{v_{4(k-1)}, v_{4(k-1)+2}\right\}, \text { untuk } i=4(k-1)+1
\end{array}\right.
$$

Terdapat empat kemungkinan nilai $n$ pada graf $C_{n}$ yaitu terdapat $m \in \mathbb{N}$ sehingga $n=$ $4 m, n=4 m+1, n=4 m+2$, atau $n=4 m+3$.

i. Untuk $n=4 m$. Diambil sebarang titik yang bertetangga $x, y \in V\left(C_{n}\right)-W$, terdapat tiga kemungkinan yaitu

$$
\begin{aligned}
& x=v_{4(k-1)+2} \text { dan } y=v_{4(k-1)+3} \text { dengan } k=1,2, \ldots,\left\lceil\frac{n}{4}\right\rceil, \\
& x=v_{4(k-1)-1} \text { dan } y=v_{4(k-1)} \text { dengan } k=2,3, \ldots,\left\lceil\frac{n}{4}\right\rceil \text { atau }
\end{aligned}
$$


$x=v_{n}$ dan $y=v_{n-1}$. Oleh karena itu, diperoleh

$\left|\left\{v_{4(k-1)+2}, v_{4(k-1)+3}\right\} \cap N\left(v_{i}\right)\right|=\left|\left\{v_{4(k-1)+2}\right\}\right|=1$ untuk $k=1$,

$\left|\left\{v_{n}, v_{(n-1)}\right\} \cap N\left(v_{i}\right)\right|=\left|\left\{v_{n}\right\}\right|=1$ untuk $i=1$,

$\left|\left\{v_{4(k-1)-1}, v_{4(k-1)}\right\} \cap N\left(v_{i}\right)\right|=\left|\left\{v_{4(k-1)}\right\}\right|=1$ untuk $i=4(k-1)+1$, atau

$\left|\left\{v_{4(k-1)+2}, v_{4(k-1)+3}\right\} \cap N\left(v_{i}\right)\right|=\left|\left\{v_{4(k-1)+2}\right\}\right|=1$ untuk $i=4(k-1)+1$.

Berdasarkan uraian diatas $W$ merupakan himpunan pembeda ketetanggaan lokal.

ii. Untuk $n=4 m+1$ dan $n=4 m+2$. Diambil sebarang titik yang bertetangga $x, y \in$ $V\left(C_{n}\right)-W$, terdapat dua kemungkinan yaitu

$x=v_{4(k-1)+2}$ dan $y=v_{4(k-1)+3}$ dengan $k=1,2, \ldots,\left\lceil\frac{n}{4}\right\rceil-1$, atau

$x=v_{4(j-1)-1}$ dan $y=v_{4(j-1)}$ dengan $j=2,3, \ldots,\left\lceil\frac{n}{4}\right\rceil$.

Oleh karena itu:

$\left|\left\{v_{4(k-1)+2}, v_{4(k-1)+3}\right\} \cap N\left(v_{i}\right)\right|=\left|\left\{v_{4(k-1)+2}\right\}\right|=1$ untuk $k=1$,

$\left|\left\{v_{4(k-1)-1}, v_{4(k-1)}\right\} \cap N\left(v_{i}\right)\right|=\left|\left\{v_{4(k-1)}\right\}\right|=1$ untuk $i=4 m+1$ dan $k=m+1$,

$\left|\left\{v_{4(k-1)-1}, v_{4(k-1)}\right\} \cap N\left(v_{i}\right)\right|=\left|\left\{v_{4(k-1)}\right\}\right|=1$ untuk $i=4(k-1)+1$, atau

$\left|\left\{v_{4(k-1)+2}, v_{4(k-1)+3}\right\} \cap N\left(v_{i}\right)\right|=\left|\left\{v_{4(k-1)+2}\right\}\right|=1$ untuk $i=4(k-1)+1$.

Berdasarkan uraian di atas $W$ merupakan himpunan pembeda ketetanggaan lokal dengan $|W|=\left\lceil\frac{n}{4}\right\rceil$

iii. Sedangkan untuk $n=4 m+3$. Diambil sebarang titik yang bertetangga $x, y \in$ $V\left(C_{n}\right)-W$, terdapat dua kemungkinan yaitu

$x=v_{4(k-1)+2}$ dan $y=v_{4(k-1)+3}$ dengan $k=1,2, \ldots,\left\lceil\frac{n}{4}\right\rceil$ atau

$x=v_{4(k-1)-1}$ dan $y=v_{4(k-1)}$ dengan $k=2,3, \ldots,\left\lceil\frac{n}{4}\right\rceil$.

Oleh karena itu:

$\left|\left\{v_{4(k-1)+2}, v_{4(k-1)+3}\right\} \cap N\left(v_{i}\right)\right|=\left|\left\{v_{4(k-1)+2}\right\}\right|=1$ untuk $k=1$, atau

$\left|\left\{v_{4(k-1)-1}, v_{4(k-1)}\right\} \cap N\left(v_{i}\right)\right|=\left|\left\{v_{4(k-1)}\right\}\right|=1$ untuk $i=4(k-1)+1$.

Berdasarkan uraian di atas $W$ merupakan himpunan pembeda ketetanggaan lokal dengan $|W|=\left\lceil\frac{n}{4}\right\rceil$

Selanjutnya ditunjukkan bahwa $W$ merupakan himpunan pembeda ketetanggaan lokal minimal. Diambil sebarang $U \subseteq V\left(C_{n}\right)$ dengan $|U|<|W|$. Terdapat tiga kasus yaitu $n=4,4<n \leq 8$, atau $n>8$

(i) Untuk $n=4, \quad|U|<|W|=\left\lceil\frac{n}{4}\right\rceil=1$ akibatnya $U=\emptyset$. Berdasarkan Definisi himpunan pembeda ketetanggaan lokal maka $U$ bukan merupakan himpunan pembeda ketetanggaan lokal.

(ii) Untuk $4<n \leq 8,|U|<|W|=\left\lceil\frac{n}{4}\right\rceil=2$ akibatnya $|U|=1$. Misalkan $U=\left\{v_{i}\right\}$. Karena $\left|V\left(C_{n}\right)-U\right| \geq 4$ maka terdapat pasangan titik bertetanga $v_{j}, v_{j+1} \in$ 
$V\left(P_{n}\right)-U$ dengan $d\left(v_{i}, v_{j}\right)>1$ atau $d\left(v_{i}, v_{j+1}\right)>1$ sehingga $\mid\left\{v_{j}, v_{j+1}\right\} \cap$ $N\left(v_{i}\right) \mid=0 \neq 1$. Berdasarkan Definisi himpunan pembeda ketetanggaan lokal maka $U$ bukan merupakan himpunan pembeda ketetanggaan lokal.

(iii) Untuk $n>8$. Terdapat $v_{i}, v_{j} \in U$ dengan $i<j, l\left(v_{i}-v_{j}\right)>5$. Berdasarkan Lema $2.1 U$ bukan himpunan pembeda ketetanggaan lokal.

Oleh karena itu $W$ merupakan basis ketetanggaan lokal dan $\operatorname{dim}_{A l}\left(C_{n}\right)=\left\lceil\frac{n}{4}\right\rceil$

Teorema 2.4 [4]. $\operatorname{dim}_{A l}\left(S_{n}\right)=1$ dengan $n \geq 2$

Bukti. Misalkan $V\left(C_{n}\right)=\left\{v_{1}, v_{2}, \ldots, v_{n-1}, v_{n}\right\}, \quad E\left(C_{n}\right)=\left\{\left(v_{i}, v_{n}\right) \cup\left(v_{i}, v_{i+1}\right) \mid i=\right.$ $1,2, \ldots, n-1\}$, dan $W=\left\{v_{1}\right\}$. Diambil sebarang titik yang bertetangga $x, y \in V\left(S_{n}\right)-$ $W$, yaitu $x=v_{0}$ dan $y=v_{r}$ dengan $r=2,3, \ldots, n$. Karena $\left|\left\{v_{0}, v_{r}\right\} \cap N\left(v_{i}\right)\right|=\left|\left\{v_{0}\right\}\right|=$ 1 , maka $W$ merupakan himpunan pembeda ketetanggaan lokal. Karena $|W|=1$ maka $\operatorname{dim}_{A l}\left(S_{n}\right)=1$

Teorema 2.5 [4]. $\operatorname{dim}_{A l}(G)=n-1$ jika dan hanya jika $G \cong K_{n}$ dengan $n \geq 2$.

Bukti. $\quad \Leftrightarrow)$ Misalkan $V\left(K_{n}\right)=\left\{v_{1}, v_{2}, \ldots, v_{n}\right\}, \quad E\left(K_{n}\right)=\left\{\left(v_{i}, v_{j}\right)\right.$ dengan $i, j=$ $1,2, \ldots, n$ dan $i \neq j\}$ dengan $n \geq 2$, dan $W=\left\{v_{1}, v_{2}, \ldots, v_{n-1}\right\}$ sehingga $|W|=n-1$. Karena tidak terdapat pasangan titik yang bertetangga $x, y \in V\left(K_{n}\right)-W$, maka $W$ adalah himpunan pembeda ketetanggaan lokal. Selanjutnya ditunjukkan bahwa $|W|$ merupakan basis ketetanggaan lokal. Dipilih $U \subseteq V\left(K_{n}\right)$ dengan $|U|<|W|$. Terdapat dua kasus yaitu $n=2$ atau $n>2$.

(i) Untuk $n=2,|U|<|W|=n-1=1$ akibatnya $U=\emptyset$. Berdasarkan Definisi himpunan pembeda ketetanggaan lokal maka $U$ bukan merupakan himpunan pembeda ketetanggaan lokal.

(ii) Untuk $n=3,|U|<|W|=n-1=2$ akibatnya $|U|=1$. Tanpa mengurangi keumuman bukti misalkan $U=\left\{v_{1}\right\}$. Karena pasangan titik bertetangga $v_{2}, v_{3} \in$ $V\left(K_{n}\right)-U$ dan $\left|\left\{v_{2}, v_{3}\right\} \cap N\left(v_{1}\right)\right|=2 \neq 1$, maka $U$ bukan merupakan himpunan pembeda ketetanggaan lokal.

(iii) Untuk $n>3$, untuk setiap $v_{i} \in U$ maka untuk setiap pasangan titik bertetangga $v_{k}, v_{t} \in V\left(K_{n}\right)-U \quad, \quad v_{k}, v_{t} \in N\left(v_{i}\right) \quad$ sehingga $\quad\left|\left\{v_{k}, v_{t}\right\} \cap N\left(v_{i}\right)\right|=2 \neq 1$. Berdasarkan Definisi himpunan pembeda ketetanggaan lokal maka $U$ bukan merupakan himpunan pembeda ketetanggaan lokal.

Oleh karena itu $W$ merupakan basis ketetanggaan lokal. Terbukti bahwa $\operatorname{dim}_{A l}\left(K_{n}\right)=$ $n-1$. Dengan demikian jika $G \cong K_{n}$ maka $\operatorname{dim}_{A l}(G)=n-1$. 
$(\Rightarrow)$ Misalkan $\operatorname{dim}_{A l}(G)=n-1$ dan andaikan $G ¥ K_{n}$, sehingga terdapat $v_{i}, v_{k} \in V(G)$ dengan $\left(v_{i}, v_{k}\right) \notin E(G)$. Dipilih $W^{\prime}=V(G)-\left\{v_{i}, v_{k}\right\}$ sehingga $V(G)-W^{\prime}=\left\{v_{i}, v_{k}\right\}$. Karena tidak terdapat pasangan titik bertetangga $x, y \in V(G)-W^{\prime}$, maka $W^{\prime}$ adalah himpunan pembeda ketetanggaan lokal dengan $\left|W^{\prime}\right|=n-2$, kontradiksi dengan $\operatorname{dim}_{A l}(G)=n-1$.

Berdasarkan uraian diatas, terbukti bahwa $\operatorname{dim}_{A l}(G)=n-1$ jika dan hanya jika $G \cong K_{n}$ dengan $n \geq 2$

Saputro dkk [7] menyajikan definisi operasi comb pada graf. Graf $G \mathbf{o} H$ merupakan graf hasil kali comb dari graf terhubung $G$ dan $H$. Misalkan $V(G)=\left\{v_{1}, v_{2}, \ldots, v_{n}\right\}$ dan $V(H)=\left\{u_{1}, u_{2}, \ldots, u_{m}\right\}$ dengan $n, m \geq 2$. Titik cangkok pada $H$ diasumsikan sebagai $u_{1}$. Titik $v_{i} \in V(G)$ di graf $G \mathbf{o} H$ dinotasikan sebagai $v_{i 1}$, sedangkan titik $u_{j} \in V(H), j \neq 1$ di graf $G \mathbf{o} H$ dinotasikan sebagai $v_{i j}$. Himpunan $I=\left\{v_{i 1} \mid i=1,2, \ldots, n\right\}$ disebut induk, sedangkan himpunan daun ke $i$ disebut $H^{i}=\left\{v_{i 2}, v_{i 3}, \ldots, v_{i m} \mid i=1,2, \ldots, n\right\}$.

Misalkan $G$ dan $H$ adalah graf terhubung, $V(G)=\left\{v_{1}, v_{2}, v_{3}, \ldots, v_{n}\right\}$, dan $o$ adalah titik cangkok di $H$. Graf $G \boldsymbol{k}$-comb $H$ dinotasikan dengan $G \mathbf{o}_{\boldsymbol{k}} H$ adalah graf yang diperoleh dengan mengambil satu salinan $G$ dan $n k$ salinan dari $H$, yaitu $H_{11}, H_{12}, H_{13}, \ldots$, $H_{1 k}, H_{21}, H_{22}, \mathrm{H}_{23}, \ldots, H_{2 k}, \ldots ., H_{n 1}, H_{n 2}, H_{n 3}, \ldots, H_{n k}$ dan merekatkan setiap salinan ke- $i j$, $i=1,2,3, \ldots, n ; j=1,2,3, \ldots k$ dari graf $H$ di titik cangkok $o_{i j}$ pada titik $v_{i}$ dari graf $G$, dengan $o_{i j}$ merupakan salinan titik $o$ di $H_{i j}$ [8]. Apabila $k=1$ maka berlaku $G \mathbf{o}_{\boldsymbol{k}} H=$ $G \mathbf{o} H$. Sedangkan graf $G \mathbf{o}_{k} H$ merupakan graf hasil kali $k$-comb dari graf terhubung $G$ dan $H$. Untuk $k=1$, penamaan titik mengikuti graf $G o H$. Untuk $k \geq 2$, misalkan $V(G)=$ $\left\{v_{1}, v_{2}, \ldots, v_{n}\right\}$ dan $V(H)=\left\{u_{1}, u_{2}, \ldots, u_{m}\right\}$ dengan $n, m \geq 2$. Titik cangkok pada $H$ diasumsikan sebagai $u_{1}$. Titik $v_{i} \in V(G)$ di graf $G \mathbf{o}_{\boldsymbol{k}} H$ dinotasikan sebagai $v_{i 101}$, sedangkan titik $u_{j} \in V(H), j \neq 1$ di graf $G \mathbf{o}_{k} H$ dinotasikan sebagai $v_{i t j}$. Himpunan $I=$ $\left\{v_{i 01} \mid i=1,2, \ldots, n\right\}$ disebut induk, sedangkan $k$ salinan daun ke $i$ disebut $H^{i t}=$ $\left\{v_{i t 2}, v_{i t 3}, \ldots, v_{i t m}\right\}$ dengan $i=1,2, \ldots, n$ dan $t=1,2, \ldots, k$.

Teorema 2.6 Misalkan $G$ graf terhubung berordo $n \geq 2$ dan graf $K_{m}$ berordo $m \geq 3$. Jika $\gamma(G)$ merupakan bilangan dominasi pada graf $G$, maka

$$
\operatorname{dim}_{A L}\left(G \mathbf{o} K_{m}\right)=|V(G)|\left(\operatorname{dim}_{A l}\left(K_{m}\right)-1\right)+\gamma(G)
$$

Bukti. Misalkan $S=\left\{v_{n_{1}}, v_{n_{2}}, \ldots, v_{n_{\gamma(G)}}\right\} \subseteq V(G)$ merupakan sebarang himpunan dominasi dari graf $G$, selanjutnya berdasarkan penamaan titik pada graf hasil operasi kali comb himpunan $S$ dapat ditulis sebagai $S^{*}=\left\{v_{n_{1} 1}, v_{n_{2} 1}, \ldots, v_{\left.n_{\gamma(G)}\right)}\right\}$. Berdasarkan Teorema 2.5, himpunan $B_{i}=\left\{v_{i 1}, v_{i 2}, \ldots, v_{i(m-1)}\right\}$ dengan $i=1,2, \ldots, n$ merupakan basis ketetanggaan lokal graf $K_{m}^{i}$. Dipilih $W=S^{*} \bigcup_{i=1}^{n}\left(B_{i}-\left\{v_{i 1}\right\}\right)$. Diambil sebarang 
titik yang bertetangga $x, y \in V\left(G \mathbf{o} K_{m}\right)-W$, terdapat dua kasus yaitu $x, y \in I-S^{*}$ atau $x \in I-S^{*}$ dan $y \in\left(B_{i}-\left\{v_{i 1}\right\}\right)$.

(i) Jika $x, y \in I-S^{*}, x=v_{r 1}$ dan $y=v_{k 1}$ dengan $r, k \neq n_{i}, i=1,2, \ldots, \gamma(G)$. Dipilih $v_{r 2} \in W$. Karena $d\left(v_{r 1}, v_{r 2}\right)=1$ atau $d\left(v_{k 1}, v_{r 2}\right)>1$ maka $\mid N\left(v_{r 2}\right) \cap$ $\left\{v_{r 1}, v_{k 1}\right\}|=|\left\{v_{r 1}\right\} \mid=1$.

(ii) Jika $x \in I-S^{*}$ dan $y \in\left(B_{i}-\left\{v_{i 1}\right\}\right)$, sehingga $x=v_{r 1}$ dan $y=v_{r m}$ dengan $r \neq$ $n_{i}, i=1,2, \ldots, \gamma(G)$. Karena $S^{*}$ merupakan himpunan dominasi dari induk, maka terdapat $v_{n_{k} 1} \in S^{*}$. Karena $d\left(v_{r 1}, v_{n_{k} 1}\right)=1$ dan $d\left(v_{r m}, v_{n_{k} 1}\right)>1$ maka $\left|N\left(v_{n_{k} 1}\right) \cap\left\{v_{r 1}, v_{r m}\right\}\right|=\left|\left\{v_{r 1}\right\}\right|=1$.

Oleh karena itu $W$ merupakan himpunan pembeda ketetanggaan lokal. Selanjutnya ditunjukkan bahwa $W$ merupakan basis ketetanggaan lokal. Diambil sebarang $W^{\prime} \subseteq$ $V\left(G \mathbf{o} K_{m}\right),\left|W^{\prime}\right|<|W|$. Terdapat dua kemungkinan yaitu $W^{\prime}=I^{\prime} \cup_{i=1}^{n} H^{\prime}$ dengan $I^{\prime} \subseteq$ $I,\left|I^{\prime}\right|<\gamma(G)$, dan $\left|H^{\prime}\right|=\left|B_{i}-\left\{v_{i 1}\right\}\right|$ atau $W^{\prime}=I^{\prime} \bigcup_{i=1}^{n} H^{\prime}$ dengan $\left|I^{\prime}\right|=\gamma(G), H^{\prime} \subseteq$ $\bigcup_{i=1}^{n} K_{m}^{i}$, dan $\left|H^{\prime}\right|<\left|B_{i}-\left\{v_{i 1}\right\}\right|$.

a. Untuk $W^{\prime}=I^{\prime} \bigcup_{i=1}^{n} H^{\prime}$, dengan $I^{\prime} \subseteq I,\left|I^{\prime}\right|<\gamma(G)$, dan $\left|H^{\prime}\right|=\left|B_{i}-\left\{v_{i 1}\right\}\right|$. Karena $I^{\prime}$ bukan merupakan himpunan dominasi minimal, maka terdapat titik $v_{r 1} \in I-I^{\prime}$ sehingga $d\left(v_{r 1}, v_{n_{k} 1}\right)>1, v_{n_{k} 1} \in I^{\prime}$. Terdapat pasangan titik bertetangga $v_{r 1}, v_{r h} \in$ $V\left(G \mathbf{o} K_{m}\right)-W^{\prime}$ dengan $h \neq 1$. Diambil sebarang $x \in W^{\prime}$, maka terdapat dua kemungkinan yaitu $x=v_{n_{k} 1}, v_{n_{k} 1} \in I^{\prime}$ atau $=v_{i h}, h \neq 1, v_{i h} \in H^{\prime}$.

i. Jika $x=v_{n_{k} 1}$ maka $v_{r 1}, v_{r h} \notin N(x)$. Oleh karena itu $\left|\left\{v_{r 1}, v_{r h}\right\} \cap N(x)\right| \neq 1$.

ii. Jika $x=v_{i h}, h \neq 1$ maka terdapat dua kemungkinan yaitu $v_{r 1}, v_{r h} \notin N(x)$ untuk $i \neq r$ atau $v_{r 1}, v_{r h} \in N(x)$ untuk $i=r$. Akibatnya $\left|\left\{v_{r 1}, v_{r h}\right\} \cap N(x)\right| \neq$ 1. Oleh karena itu $W^{\prime}$ bukan himpunan pembeda ketetanggaan lokal.

b. Selanjutnya untuk $W^{\prime}=I^{\prime} \cup_{i=1}^{n} H^{\prime}$, dengan $I^{\prime} \subseteq I,\left|I^{\prime}\right|=\gamma(G),\left|H^{\prime}\right|<\left|B_{i}-\left\{v_{i 1}\right\}\right|$, dan $H^{\prime} \subseteq \bigcup_{i=1}^{n} K_{m}^{i}$. Terdapat $K_{m}^{i}$ sehingga maksimal terdapat $\left(\left|B_{i}-\left\{v_{i 1}\right\}\right|-1\right)$ titik yang menjadi anggota $W^{\prime}$. Tanpa mengurangi keumuman bukti, misalkan $i=1$ sehingga maksimal terdapat $\left(\left|B_{1}-\left\{v_{11}\right\}\right|-1\right)$ titik yang menjadi anggota $W^{\prime}$. Akibatnya terdapat pasangan titik bertetangga $v_{12}, v_{13} \in V\left(G \mathbf{o} K_{m}\right)-W^{\prime}$. Diambil sebarang $x \in W^{\prime}$, maka terdapat dua kemungkinan yaitu $x=v_{n_{k} 1}, v_{n_{k} 1} \in I^{\prime}$ atau $x=v_{i t}, t=(4,5, \ldots, m), v_{i t} \in H^{\prime}$.

i. Jika $x=v_{n_{k} 1}$ maka $v_{12}, v_{13} \notin N(x)$. Akibatnya $\left|\left\{v_{12}, v_{13}\right\} \cap N(x)\right| \neq 1$.

ii. Sedangkan jika $x=v_{i t}$ maka $v_{12}, v_{13} \in N(x)$. Akibatnya $\mid\left\{v_{12}, v_{13}\right\} \cap$ $N(x) \mid \neq 1$.

Oleh karena itu $W^{\prime}$ bukan himpunan pembeda ketetanggaan lokal.

Berdasarkan uraian di atas $W^{\prime}$ bukan himpunan pembeda ketetanggaan lokal. Oleh karena itu $W$ merupakan basis ketetanggaan lokal dari graf $G \mathbf{o} K_{m}$. Jadi $\operatorname{dim}_{A l}\left(G \mathbf{o} K_{m}\right)=|W|=$ $|V(G)|\left(\operatorname{dim}_{A l}\left(K_{m}\right)-1\right)+\gamma(G)$ 
Munawaroh [9] menyajikan definisi operasi kali comb tingkat $k$ dari graf $G$ dan graf $H$ yang dinotasikan dengan $G \mathbf{o}^{k} H$.

Akibat 2.7. Misalkan $G$ graf terhubung berordo $n \geq 2$ dan graf $K_{m}$ berordo $m \geq 3$. Jika $k \geq 1$ maka

$$
\operatorname{dim}_{A L}\left(G \mathbf{o}^{k} K_{m}\right)=\left|V\left(G \mathbf{o}^{k-1} K_{m}\right)\right|\left(\operatorname{dim}_{A l}\left(K_{m}\right)-1\right)+\gamma\left(G \mathbf{o}^{k-1} K_{m}\right)
$$

Bukti. Misalkan $G^{\prime}=G \mathbf{o}^{k-1} K_{m}$, akibatnya $G \mathbf{o}^{k} K_{m}=G^{\prime} \mathbf{o} K_{m}$. Bedasarkan Teorema 2.1, diperoleh $\operatorname{dim}_{A l}\left(G \mathbf{o}^{k} K_{m}\right)=\left|V\left(G \mathbf{o}^{k-1} K_{m}\right)\right|\left(\operatorname{dim}_{A l}\left(K_{m}\right)-1\right)+\gamma\left(G \mathbf{o}^{k-1} K_{m}\right)$

Teorema 2.8. Misalkan $G$ adalah graf terhubung berorodo $n \geq 2$ dan $H$ adalah graf $K_{m}$ berordo $m \geq 3$. Jika $\gamma(G)$ merupakan bilangan dominasi dari graf $G$ dan $k>1$ maka

$$
\operatorname{dim}_{A L}\left(G \mathbf{o}_{\boldsymbol{k}} K_{m}\right)=k|V(G)|\left(\operatorname{dim}_{A L}\left(K_{m}\right)-1\right)+\gamma(G)
$$

Bukti. Misalkan $S=\left\{v_{n_{1}}, v_{n_{2}}, \ldots, v_{n_{\gamma(G)}}\right\} \subseteq V(G)$ merupakan himpunan dominasi minimal dari graf $G$, selanjutnya berdasarkan penamaan titik pada graf hasil operasi kali $k$-comb himpunan $S$ dapat ditulis sebagai $S^{*}=\left\{v_{n_{1} 01}, v_{n_{2} 01}, \ldots, v_{n_{\gamma(G)} 01}\right\}$. Berdasarkan Teorema 2.5, himpunan $B_{i t}=\left\{v_{i 01}, v_{i t 2}, \ldots, v_{i t(m-1)}\right\}$ dengan $i=1,2, \ldots, n$ dan $t=$ $1,2, \ldots, k$ merupakan basis ketetanggaan lokal graf $K_{m}^{i t}$. Dipilih $W=S^{*} \bigcup_{i=1}^{n k}\left(B_{i t}-\right.$ $\left.\left\{v_{i 01}\right\}\right)$. Diambil sebarang titik yang bertetangga $x, y \in V\left(G \mathbf{o}_{k} K_{m}\right)-W$, terdapat dua kasus yaitu $x, y \in I-S^{*}$ atau $x \in I-S^{*}$ dan $y \in\left(B_{i t}-\left\{v_{i 01}\right\}\right)$.

i. Jika $x, y \in I-S^{*}, x=v_{r 01}$ dan $y=v_{k 01}$ dengan $r, k \neq n_{i}, i=1,2, \ldots, \gamma(G)$. Dipilih $v_{r t 2} \in W$ dengan $t=1,2, \ldots, k$. Karena $d\left(v_{r 01}, v_{r t 2}\right)=1$ atau $d\left(v_{k 01}, v_{r t 2}\right)>1$ maka $\left|N\left(v_{r t 2}\right) \cap\left\{v_{r 01}, v_{k 01}\right\}\right|=\left|\left\{v_{r 01}\right\}\right|=1$.

ii. Jika $x \in I-S^{*}$ dan $y \in\left(B_{i t}-\left\{v_{i 01}\right\}\right)$, sehingga $x=v_{r 01}$ dan $y=v_{r t m}$ dengan $r \neq$ $n_{i}, i=1,2, \ldots, \gamma(G)$ dan $t=1,2, \ldots, k$. Karena $S^{*}$ merupakan himpunan dominasi minimal dari induk, maka terdapat $v_{n_{k} 01} \in S^{*}$. Karena $d\left(v_{r 01}, v_{n_{k} 01}\right)=1$ dan $d\left(v_{r t m}, v_{n_{k} 01}\right)>1$ maka $\left|N\left(v_{n_{k} 01}\right) \cap\left\{v_{r 01}, v_{r t m}\right\}\right|=\left|\left\{v_{r 01}\right\}\right|=1$.

Berdasarkan uraian diatas $W$ merupakan himpunan pembeda ketetanggaan lokal.

Selanjutnya ditunjukkan bahwa $W$ merupakan basis ketetanggaan lokal minimal. Diambil sebarang $W^{\prime} \subseteq V\left(G \mathbf{o}_{\boldsymbol{k}} K_{m}\right), \quad\left|W^{\prime}\right|<|W|$. Terdapat dua kemungkinan yaitu $W^{\prime}=$ $I^{\prime} \bigcup_{i=1}^{n} H^{\prime}$ dengan $I^{\prime} \subseteq I,\left|I^{\prime}\right|<\gamma(G)$, dan $\left|H^{\prime}\right|=\left|B_{i t}-\left\{v_{i 01}\right\}\right|$ atau $W^{\prime}=I^{\prime} \bigcup_{i=1}^{n k} H^{\prime}$ dengan $\left|I^{\prime}\right|=\gamma(G), H^{\prime} \subseteq \bigcup_{i=1}^{n k} K_{m}^{i t}$, dan $\left|H^{\prime}\right|<\left|B_{i t}-\left\{v_{i 01}\right\}\right|$. 
a. Untuk $W^{\prime}=I^{\prime} \bigcup_{i=1}^{n k} H^{\prime}$ dengan $I^{\prime} \subseteq I, \quad\left|I^{\prime}\right|<\gamma(G)$, dan $\left|H^{\prime}\right|=\left|B_{i t}-\left\{v_{i 01}\right\}\right|$. Karena $I^{\prime}$ bukan merupakan himpunan dominasi minimal, maka terdapat titik $v_{r 01} \in$ $I-I^{\prime}$ sehingga $d\left(v_{r 01}, v_{n_{k} 01}\right)>1, v_{n_{k} 01} \in I^{\prime}$. Terdapat pasangan titik bertetangga $v_{r 01}, v_{r t h} \in V\left(G \mathbf{o}_{\boldsymbol{k}} K_{m}\right)-W^{\prime}$ dengan $h \neq 1$. Diambil sebarang $x \in W^{\prime}$, maka terdapat dua kemungkinan yaitu $x=v_{n_{k} 01}, v_{n_{k} 01} \in I^{\prime}$ atau $x=v_{i t h}, h=2,3 \ldots, m$. Jika $x=v_{n_{k} 01}$ maka $v_{r 01}, v_{r t h} \notin N(x)$. Sedangkan jika $x=v_{i t h}, h \neq 1$ maka terdapat dua kemungkinan yaitu $v_{r 01}, v_{r t h} \notin N(x)$ untuk $i \neq r$ atau $v_{r 01}, v_{r t h} \in$ $N(x)$ untuk $i=r$. Akibatnya $\left|\left\{v_{r 01}, v_{r t h}\right\} \cap N(x)\right| \neq 1$. Oleh karena itu $W^{\prime}$ bukan himpunan pembeda ketetanggaan lokal.

b. Selanjutnya untuk $W^{\prime}=I^{\prime} \cup_{i=1}^{n} H^{\prime}, W^{\prime}=I^{\prime} \bigcup_{i=1}^{n k} H^{\prime}$ dengan $\left|I^{\prime}\right|=\gamma(G), H^{\prime} \subseteq$ $\bigcup_{i=1}^{n k} K_{m}^{i t}$, dan $\left|H^{\prime}\right|<\left|B_{i t}-\left\{v_{i 01}\right\}\right|$. Terdapat $K_{m}^{i t}$ sehingga maksimal terdapat $\left|B_{i t}-\left\{v_{i 01}\right\}\right|-1$ titik yang menjadi anggota $W^{\prime}$. Tanpa mengurangi keumuman bukti, misalkan $i=1$ dan $t=1$ sehingga maksimal terdapat $\left(\left|B_{11}-\left\{v_{101}\right\}\right|-1\right)$ titik yang menjadi anggota $W^{\prime}$. Akibatnya terdapat pasangan titik bertetangga $v_{11 h}, v_{11 q} \in V\left(G \mathbf{o}_{\boldsymbol{k}} K_{m}\right)-W^{\prime}$ dengan $h, q \neq 1, h \neq q$. Diambil sebarang $x \in W^{\prime}$, maka terdapat dua kemungkinan yaitu $x=v_{n_{k} 01}, v_{n_{k} 01} \in I^{\prime}$ atau $x=v_{i t p}, p \neq$ $1, p \neq h, p \neq q$, dan $v_{i t p} \in H^{\prime}$.

i. $\quad$ Jika $x=v_{n_{k} 01}$ maka $v_{i t h}, v_{i t q} \notin N(x)$. Akibatnya $\left|\left\{v_{11 h}, v_{11 q}\right\} \cap N(x)\right| \neq 1$.

ii. Sedangkan jika $x=v_{i t p}$ maka $v_{11 h}, v_{11 q} \in N(x)$. Akibatnya $\mid\left\{v_{11 h}, v_{11 q}\right\} \cap$ $N(x) \mid \neq 1$.

Oleh karena itu $W^{\prime}$ bukan himpunan pembeda ketetanggaan lokal.

Berdasarkan uraian di atas $W^{\prime}$ bukan himpunan pembeda ketetanggaan lokal. Oleh karena itu $W$ merupakan basis ketetanggaan lokal dari graf $G \mathbf{o}_{\boldsymbol{k}} K_{m}$. Jadi $\operatorname{dim}_{A l}\left(G \mathbf{o}_{\boldsymbol{k}} K_{m}\right)=$ $|W|=k|V(G)|\left(\operatorname{dim}_{A l}\left(K_{m}\right)-1\right)+\gamma(G)$

Teorema 2.9. Misalkan $G$ graf terhubung berordo $n \geq 2$, graf $S_{m}$ berordo $m \geq 2$. Jika titik cangkok $o$ bukan merupakan titik dominasi pada graf $S_{m}$ maka

$$
\operatorname{dim}_{A L}\left(G \mathbf{o} S_{m}\right)=|V(G)|
$$

Bukti. Misalkan $W=I=\left\{v_{i 1} \mid i=1,2, \ldots, n\right\}$. Diambil sebarang titik yang bertetangga $x, y \in V\left(G \mathbf{o} S_{m}\right)-W$, akibatnya $x=v_{i 0}$ dan $y=v_{i j}$ dengan $j=2,3, \ldots, m$. Oleh karena itu $\left|\left\{v_{i 0}, v_{i j}\right\} \cap N\left(v_{i 1}\right)\right|=\left|\left\{v_{i 0}\right\}\right|=1$. Berdasarkan uraian diatas $W$ merupakan himpunan pembeda ketetanggaan lokal.

Selanjutnya ditunjukkan bahwa $W$ merupakan himpunan pembeda ketetanggaan lokal minimal. Diambil sebarang $W^{\prime} \subseteq V\left(G \mathbf{o} S_{m}\right),\left|W^{\prime}\right|<|W|$. Terdapat tiga kemungkinan yaitu $W^{\prime} \subseteq I, W^{\prime} \subseteq \bigcup_{i=1}^{n} S_{m}^{i}$, atau $W^{\prime} \subseteq B \cup P$, dengan $B \subseteq I$ dan $P \subseteq \bigcup_{i=1}^{n} S_{m}^{i}$. 
a. Untuk $W^{\prime} \subseteq I$. Tanpa mengurangi keumuman bukti, misalkan $v_{11} \notin W^{\prime}$. Akibatntya terdapat pasangan titik bertetangga $v_{10}, v_{12} \in V\left(G o S_{m}\right)-W^{\prime}$. Diambil sebaranga $v_{p 1} \in W^{\prime}$ dengan $\left(v_{p 1}, v_{10}\right)>1$ atau $d\left(v_{p 1}, v_{12}\right)>1$ sehingga $\mid\left\{v_{10}, v_{12}\right\} \cap$ $N\left(v_{p 1}\right) \mid=0 \neq 1$. Berdasarkan Definisi himpunan pembeda ketetanggaan lokal $W^{\prime}$ bukan himpunan pembeda ketetanggaan lokal.

b. Untuk $W^{\prime} \subseteq \bigcup_{i=1}^{n} S_{m}^{i}$. Tanpa mengurangi keumuman bukti, misalkan $v_{1 p} \notin W^{\prime}, p \neq$ 1. Akibatnya terdapat pasangan titik bertetangga $v_{10}, v_{12} \in V\left(G o S_{m}\right)-W^{\prime}$. Diambil sebarang $v_{p q} \in W^{\prime}$ dan $p, q \neq 1$ dengan $\left(v_{p q}, v_{10}\right)>1$ atau $d\left(v_{p q}, v_{12}\right)>1$ sehingga $\left|\left\{v_{10}, v_{12}\right\} \cap N\left(v_{p q}\right)\right|=0 \neq 1$. Berdasarkan Definisi himpunan pembeda ketetanggaan lokal $W^{\prime}$ bukan himpunan pembeda ketetanggaan lokal.

c. Sedangkan untuk $W^{\prime} \subseteq B \cup P$, dengan $B \subseteq I$ dan $P \subseteq \bigcup_{i=1}^{n} S_{m}^{i}$. Tanpa mengurangi keumuman bukti, misalkan $v_{1 p} \notin W^{\prime}, p \in\{0,1, \ldots, m\}$. Akibatnya terdapat pasangan titik bertetangga $v_{1 x}, v_{1 y} \in V\left(G o S_{m}\right)-W^{\prime}$, dengan $x, y \in\{0,1, \ldots, m\}, x \neq y$. Diambil sebarang $v_{k d} \in W^{\prime}, k \neq 1$ dengan $\left(v_{k d}, v_{1 x}\right)>1$ atau $d\left(v_{k d}, v_{1 y}\right)>1$ sehingga $\left|\left\{v_{1 x}, v_{1 y}\right\} \cap N\left(v_{k d}\right)\right|=0 \neq 1$. Berdasarkan Definisi himpunan pembeda ketetanggaan lokal $W^{\prime}$ bukan himpunan pembeda ketetanggaan lokal.

Oleh karena itu $W^{\prime}$ bukan himpunan pembeda ketetanggaan lokal. Jadi $W$ merupakan basis ketetanggaan lokal dan $\operatorname{dim}_{A l}\left(G \mathbf{o} S_{m}\right)=|V(G)|$

Akibat 2.10. Misalkan $G$ graf terhubung berordo $n \geq 2$, graf $S_{m}$ berordo $m \geq 2$, dan titik cangkok $o$ bukan merupakan titik dominasi pada graf $S_{m}$. Jika Jika $k \geq 1$ maka

$$
\operatorname{dim}_{A L}\left(G \mathbf{o}^{k} S_{m}\right)=\left|V\left(G \mathbf{o}^{k-1} S_{m}\right)\right|
$$

Bukti. Misalkan $G^{\prime}=G \mathbf{o}^{k-1} S_{m}$, akibatnya $G \mathbf{o}^{k} S_{m}=G^{\prime} \mathbf{o} S_{m}$. Bedasarkan Teorema 2.9, diperoleh $\operatorname{dim}_{A l}\left(G \mathbf{o}^{k} S_{m}\right)=\left|V\left(G \mathbf{o}^{k-1} S_{m}\right)\right|$

Teorema 2.11. Misalkan $G$ adalah graf terhubung berordo $n \geq 2$ dan $H$ adalah barisan $n$ graf $S_{m}$ berordo $m \geq 2$. Jika titik cangkok $o$ bukan merupakan titik dominan dari graf bintang $S_{m}$ dan $k \geq 1$ maka

$$
\operatorname{dim}_{A L}\left(G \mathbf{o}_{\boldsymbol{k}} S_{m}\right)=|V(G)|
$$

Bukti. Misalkan $W=I=\left\{v_{i 01} \mid i=1,2, \ldots, n\right\}$. Diambil sebarang titik yang bertetangga $x, y \in V\left(G \mathbf{o}_{\boldsymbol{k}} S_{m}\right)-W$, akibatnya $x=v_{i t 0}$ dan $y=v_{i t j}$ dengan $j=$ $2,3, \ldots, m$. Oleh karena itu $\left|\left\{v_{i t 0}, v_{i t j}\right\} \cap N\left(v_{i 01}\right)\right|=\left|\left\{v_{i t 0}\right\}\right|=1$. Berdasarkan uraian diatas $W$ merupakan himpunan pembeda ketetanggaan lokal. 
Selanjutnya ditunjukkan bahwa $W$ merupakan basis ketetanggaan lokal. Diambil sebarang $W^{\prime} \subseteq V\left(G \mathbf{o}_{k} S_{m}\right),\left|W^{\prime}\right|<|W|$. Terdapat tiga kemungkinan yaitu $W^{\prime} \subseteq I$, $W^{\prime} \subseteq \bigcup_{i=1}^{n k} S_{m}^{i t}$, atau $W^{\prime} \subseteq B \cup P$, dengan $B \subseteq I$ dan $P \subseteq \bigcup_{i=1}^{n k} S_{m}^{i t}$.

a. Untuk $W^{\prime} \subseteq I$. Tanpa mengurangi keumuman bukti, misalkan $v_{101} \notin W^{\prime}$. Akibatntya terdapat pasangan titik bertetangga $v_{1 t 0}, v_{1 t 2} \in V\left(G \mathbf{o}_{\boldsymbol{k}} S_{m}\right)-W^{\prime}$. Diambil sebaranga $v_{p 01} \in W^{\prime}$ dengan $\left(v_{p 01}, v_{1 t 0}\right)>1$ atau $d\left(v_{p 01}, v_{1 t 2}\right)>1$ sehingga $\mid\left\{v_{1 t 0}, v_{1 t 2}\right\} \cap$ $N\left(v_{p 01}\right) \mid=0 \neq 1$. Berdasarkan Definisi himpunan pembeda ketetanggaan lokal $W^{\prime}$ bukan himpunan pembeda ketetanggaan lokal.

b. Untuk $W^{\prime} \subseteq \bigcup_{i=1}^{n k} S_{m}^{i t}$ Tanpa mengurangi keumuman bukti, misalkan $v_{11 p} \notin W^{\prime}, p \neq$ 1. Akibatnya terdapat pasangan titik bertetangga $v_{110}, v_{112} \in V\left(G \mathbf{o}_{\boldsymbol{k}} S_{m}\right)-W^{\prime}$. Diambil sebarang $v_{p t q} \in W^{\prime}$ dan $p, q \neq 1$ dengan $\left(v_{p t q}, v_{110}\right)>1$ atau $d\left(v_{p t q}, v_{112}\right)>1$ sehingga $\left|\left\{v_{110}, v_{112}\right\} \cap N\left(v_{p t q}\right)\right|=0 \neq 1$. Berdasarkan Definisi himpunan pembeda ketetanggaan lokal $W^{\prime}$ bukan himpunan pembeda ketetanggaan lokal.

c. Sedangkan untuk $W^{\prime} \subseteq B \cup P$, dengan $B \subseteq I$ dan $P \subseteq \bigcup_{i=1}^{n k} S_{m}^{i t}$. Tanpa mengurangi keumuman bukti, misalkan $v_{1 t p} \notin W^{\prime}, p \in\{0,1, \ldots, m\}$. Akibatnya terdapat pasangan titik bertetangga $v_{1 t x}, v_{1 t y} \in V\left(G o S_{m}\right)-W^{\prime}$, dengan $x, y \in\{0,1, \ldots, m\}, x \neq y$. Diambil sebarang $v_{k t d} \in W^{\prime}, k \neq 1, d \in\{0,1, \ldots, m\}$ dengan $\left(v_{k t d}, v_{1 t x}\right)>1$ atau $d\left(v_{k t d}, v_{1 t y}\right)>1$ sehingga $\left|\left\{v_{1 t x}, v_{1 t y}\right\} \cap N\left(v_{k t d}\right)\right|=0 \neq 1$. Berdasarkan Definisi himpunan pembeda ketetanggaan lokal $W^{\prime}$ bukan himpunan pembeda ketetanggaan lokal.

Oleh karena itu, $W^{\prime}$ bukan himpunan pembeda ketetanggaan lokal. Jadi $W$ merupakan basis ketetanggaan lokal dari graf $G \mathbf{o}_{k} S_{m}$ dan $\operatorname{dim}_{A l}\left(G \mathbf{o}_{\boldsymbol{k}} S_{m}\right)=|V(G)|$

Teorema 2.12. Misalkan $G$ merupakan graf $C_{n}$, graf $S_{n}$, graf $K_{n}$, atau graf $P_{n}$ berordo $n \geq 2$ dan $m \geq 4$. Jika $\gamma(G)$ merupakan bilangan dominasi pada graf $G$ maka

$$
\operatorname{dim}_{A L}\left(G \mathbf{o} C_{m}\right)=\left\{\begin{array}{c}
|V(G)|\left(\operatorname{dim}_{A L}\left(C_{m}\right)-1\right)+V(G), \text { untuk } m=4 k \text { atau } m=4 k+3 \\
|V(G)|\left(\operatorname{dim}_{A L}\left(C_{m}\right)-1\right)+\gamma(G), \text { untuk } m \text { yang lain }
\end{array}\right.
$$
dengan $k \in \mathbb{N}$.

Bukti. Misalkan $G$ merupakan graf $C_{n}$, graf $S_{n}$, graf $K_{n}$, atau graf $P_{n}$ berordo $n \geq 2 . S \subseteq$ $V(G)$ dan $S=\left\{v_{n_{1}}, v_{n_{2}}, \ldots, v_{n_{\gamma(G)}}\right\}$ merupakan himpunan dominasi minimal dari graf $G$, selanjutnya berdasarkan penamaan titik pada graf hasil operasi kali comb himpunan $S$ pada $G \mathbf{o} C_{m}$ adalah $S^{*}=\left\{v_{n_{1} 1}, v_{n_{2} 1}, \ldots, v_{n_{\gamma(G)}}\right\}$. Berdasarkan Teorema 2.3, 
$B_{i}=\left\{v_{i 1}, v_{i 5}, \ldots, v_{i 4(k-1)+1}, \ldots, v_{i\left[4\left(\left[\frac{m}{4}\right]-1\right)+1\right]} \mid k \leq\left\lceil\frac{m}{4}\right]\right\}, \quad$ dengan $\quad i=1,2, \ldots, n$ merupakan basis ketetanggaan lokal graf $C_{m}^{i}$. Terdapat empat kemungkinan nilai $m$ yaitu $m=4 k, m=4 k+1, m=4 k+2$, atau $m=4 k+3$.

a. Untuk $m=4 k$ atau $m=4 k+3$. Dipilih $W=\bigcup_{i=1}^{n} B_{i}$. Diambil sepasang titik bertetangga $x, y \in V\left(G \mathbf{o} C_{m}\right)-W$, akibatnya $x, y \in C_{m}^{i}-B_{i}$. Karena $I \subseteq W$ maka berdasarkan Teorema 2.2, $W$ merupakan himpunan pembeda ketetanggaan lokal. Karena $B_{i}$ merupakan basis ketetanggaan lokal dari $C_{m}$, maka $W$ merupakan basis ketetanggaan lokal dari graf $G \mathbf{o} C_{m}$.

b. Sedangkan untuk $m=4 k+1$ atau $m=4 k+2$. Misalkan $W=S^{*} \bigcup_{i=1}^{n}\left\{v_{i 4(k-1)}\right\}$ dengan $k=2,3, \ldots,\left\lceil\frac{m}{4}\right\rceil$. Diambil sebarang titik yang bertetangga $x, y \in V\left(G \mathbf{o} C_{m}\right)-$ $W$, terdapat dua kasus yaitu $x, y \in I-S^{*}$ atau $x \in I-S^{*}$ dan $y \in C_{m}^{i}-\left\{v_{i 4(k-1)}\right\}$.

(i) Untuk $x, y \in I-S^{*}, x=v_{r 1}$ dan $y=v_{k 1}$ dengan $r, k \neq n_{i}, i=1,2, \ldots, \gamma(G)$. Dipilih $v_{i 1} \in I$ dengan $d\left(v_{i 1}, v_{r 1}\right)=1$ atau $d\left(v_{i 1}, v_{k 1}\right)>1$. Oleh karena itu $\left|N\left(v_{i 1}\right) \cap\left\{v_{r 1}, v_{k 1}\right\}\right|=\left|\left\{v_{r 1}\right\}\right|=1$.

(ii) Untuk $x \in I-S^{*}$ dan $y \in C_{m}^{i}-\left\{v_{i 4(k-1)}\right\}$, akibatnya $x=v_{r 1}$ dan $y=v_{r 2}$ dengan $r \neq n_{i}, i=1,2, \ldots, \gamma(G)$. Karena $S^{*}$ merupakan himpunan dominasi minimal dari induk, maka terdapat $v_{n_{k} 1} \in S^{*}$. Karena $d\left(v_{r_{1}}, v_{n_{k} 1}\right)=1$ dan $d\left(v_{r 2}, v_{n_{k} 1}\right)>1$ maka $\left|N\left(v_{n_{k} 1}\right) \cap\left\{v_{r 1}, v_{r 2}\right\}\right|=\left|\left\{v_{r 1}\right\}\right|=1$.

Berdasarkan uraian diatas maka $W$ merupakan himpunan pembeda ketetanggaan lokal. Selanjutnya akan ditunjukkan bahwa $W$ merupakan basis ketetanggaan lokal. Diambil sebarang $W^{\prime} \subseteq V\left(G \mathbf{o} C_{m}\right),\left|W^{\prime}\right|<|W|$. Terdapat empat kemungkinan nilai $m$ yaitu $m=$ $4 k, m=4 k+1, m=4 k+2$, atau $m=4 k+3$.

a. Untuk $m=4 k$ atau $m=4 k+3$. Karena $\left|W^{\prime}\right|<|W|$ dan $\left|W^{\prime}\right|<\left|\bigcup_{i=1}^{n} B_{i}\right|$, akibatnya terdapat $C_{m}^{i}$ sehingga maksimal terdapat $\left|B_{i}\right|-1$ titik yang menjadi anggota $W^{\prime}$. Tanpa mengurangi keumuman bukti, misalkan $i=1$ sehingga maksimal terdapat $\left|B_{1}\right|-1$ titik yang menjadi anggota $W^{\prime}$. Akibatnya $v_{1 r}, v_{1 h} \in W^{\prime}, r \neq h$, dan $l\left(v_{1 r}-v_{1 h}\right)>4$. Berdasarkan Lema 4.1.1, $W^{\prime}$ bukan merupakan himpunan pembeda ketetanggaan lokal.

b. Sedangkan untuk $m=4 k+1$ atau $m=4 k+2$. Terdapat dua kemungkinan yaitu $W^{\prime}=I^{\prime} \bigcup_{i=1}^{n} H^{\prime}$ dengan $I^{\prime} \subseteq I,\left|I^{\prime}\right|<\gamma(G)$, dan $\left|H^{\prime}\right|=\left|\bigcup_{i=1}^{n}\left\{v_{i 4(k-1)}\right\}\right|$ dengan $k=$ $2,3, \ldots,\left\lceil\frac{m}{4}\right\rceil$ atau $W^{\prime}=I^{\prime} \bigcup_{i=1}^{n} H^{\prime}$ dengan $\left|I^{\prime}\right|=\gamma(G), H^{\prime} \subseteq \bigcup_{i=1}^{n} C_{m}^{i}$, dan $\left|H^{\prime}\right|<$ $\left|\bigcup_{i=1}^{n}\left\{v_{i 4(k-1)}\right\}\right|$.

i. Untuk $W^{\prime}=I^{\prime} \bigcup_{i=1}^{n} H^{\prime}$ dengan $I^{\prime} \subseteq I,\left|I^{\prime}\right|<\gamma(G)$, dan $\left|H^{\prime}\right|=\left|\bigcup_{i=1}^{n}\left\{v_{i 4(k-1)}\right\}\right|$ dengan $k=2,3, \ldots,\left\lceil\frac{m}{4}\right]$. Karena $I^{\prime}$ bukan merupakan himpunan dominasi 
minimal, maka terdapat titik $v_{r 1} \in I-I^{\prime}$ sehingga $d\left(v_{r 1}, v_{n_{k} 1}\right)>1, v_{n_{k} 1} \in I^{\prime}$. Terdapat pasangan titik bertetangga $v_{r p}, v_{r q} \in W^{\prime}$ dengan $p \neq q$. Diambil sebarang $x \in W^{\prime}$, maka terdapat dua kemungkinan yaitu $x=v_{n_{k} 1}, v_{n_{k} 1} \in I^{\prime}$ atau $x=v_{i h}$ dengan $h \neq 1, v_{i h} \in H^{\prime}$. Jika $x=v_{n_{k} 1}$ maka $v_{r p}, v_{r q} \notin N(x)$. Sedangkan jika $x=v_{v_{i h}}$ maka $v_{r p}, v_{r q} \notin N(x)$. Akibatnya $\mid\left\{v_{r p}, v_{r q}\right\} \cap$ $N(x) \mid \neq 1$.

ii. Selanjutnya untuk $W^{\prime}=I^{\prime} \bigcup_{i=1}^{n} H^{\prime}$ dengan $\left|I^{\prime}\right|=\gamma(G), H^{\prime} \subseteq \bigcup_{i=1}^{n} C_{m}^{i}$, dan $\left|H^{\prime}\right|<\left|\bigcup_{i=1}^{n}\left\{v_{i 4(k-1)}\right\}\right|$ dengan $k=2,3, \ldots,\left\lceil\frac{m}{4}\right]$. Terdapat $C_{m}^{i}$ sehingga maksimal terdapat $\left|\left\{v_{i 4(k-1)}\right\}\right|-1$ titik yang menjadi anggota $W^{\prime}$. Tanpa mengurangi keumuman bukti, misalkan $i=1$ sehingga maksimal terdapat $\left(\left|v_{14(k-1)}\right|-1\right)$ titik yang menjadi anggota $W^{\prime}$. Akibatnya terdapat pasangan titik bertetangga $v_{1 p}, v_{1 q} \in W^{\prime}$ dengan $p \neq q$ dan $l\left(v_{1 p}-v_{1 q}\right)>4$. Berdasarkan Lema $2.1 W^{\prime}$ bukan himpunan pembeda ketetanggaan lokal.

Berdasarkan uraian diatas $W^{\prime}$ bukan himpunan pembeda ketetanggaan lokal. Oleh karena itu $W$ merupakan basis ketetanggaan lokal dan $\operatorname{dim}_{A L}\left(G \mathbf{o} C_{m}\right)=$ $\left\{|V(G)|\left(\operatorname{dim}_{A L}\left(C_{m}\right)-1\right)+V(G)\right.$, untuk $m=4 k$ atau $m=4 k+3$

$|V(G)|\left(\operatorname{dim}_{A L}\left(C_{m}\right)-1\right)+\gamma(G)$, untuk $m$ yang lain

Akibat 2.13. Misalkan $G$ merupakan graf $C_{n}$, graf $S_{n}$, graf $K_{n}$, atau graf $P_{n}$ berordo $n \geq$ 2 dan $m \geq 4$. Jika $k \geq 1$ maka

$\operatorname{dim}_{A L}\left(G \mathbf{o}^{k} C_{m}\right)$

$=\left\{\begin{array}{c}\left|V\left(G \mathbf{o}^{k-1} C_{m}\right)\right|\left(\operatorname{dim}_{A L}\left(C_{m}\right)-1\right)+V\left(G \mathbf{o}^{k-1} C_{m}\right), \text { untuk } m=4 k \text { atau } m=4 k+3 \\ \left|V\left(G \mathbf{o}^{k-1} C_{m}\right)\right|\left(\operatorname{dim}_{A L}\left(C_{m}\right)-1\right)+\gamma\left(G \mathbf{o}^{k-1} C_{m}\right), \text { untuk } m \text { yang lain }\end{array}\right.$

Bukti. Misalkan $G^{\prime}=G \mathbf{o}^{k-1} C_{m}$, akibatnya $G \mathbf{o}^{k} C_{m}=G^{\prime} \mathbf{o} C_{m}$. Bedasarkan Teorema 2.12, diperoleh $\operatorname{dim}_{A L}\left(G \mathbf{o}^{k} C_{m}\right)=$ $\left\{\begin{array}{c}\left|V\left(G \mathbf{o}^{k-1} C_{m}\right)\right|\left(\operatorname{dim}_{A L}\left(C_{m}\right)-1\right)+V\left(G \mathbf{o}^{k-1} C_{m}\right), \text { untuk } m=4 k \text { atau } m=4 k+3 \\ \left|V\left(G \mathbf{o}^{k-1} C_{m}\right)\right|\left(\operatorname{dim}_{A L}\left(C_{m}\right)-1\right)+\gamma\left(G \mathbf{o}^{k-1} C_{m}\right), \text { untuk } m \text { yang lain }\end{array}\right.$

Teorema 2.14. Misalkan $G$ merupakan graf $C_{n}$, graf $S_{n}$, graf $K_{n}$, dan graf $P_{n}$ berordo $n \geq$ 2 dan $m \geq 4$. Jika $\gamma(G)$ merupakan bilangan dominasi dari graf $G$ dan $k \geq 1$ maka

$\operatorname{dim}_{A L}\left(G \mathbf{o}_{\boldsymbol{k}} C_{m}\right)=$ $\left\{\begin{array}{c}k|V(G)|\left(\operatorname{dim}_{A L}\left(C_{m}\right)-1\right)+V(G), \text { untuk } m=4 k \text { atau } m=4 k+3 \\ k|V(G)|\left(\operatorname{dim}_{A L}\left(C_{m}\right)-1\right)+\gamma(G), \text { untuk } m \text { yang lain }\end{array}\right.$

dengan $k \in \mathbb{N}$. 
Bukti. Misalkan $G$ merupakan graf $C_{n}$, graf $S_{n}$, graf $K_{n}$, dan graf $P_{n}$ berordo $n \geq 2$. $S \subseteq$ $V(G)$ dan $S=\left\{v_{n_{1}}, v_{n_{2}}, \ldots, v_{n_{\gamma(G)}}\right\}$ merupakan himpunan dominasi minimal dari graf $G$, selanjutnya berdasarkan penamaan titik pada graf hasil operasi kali comb himpunan $S$ pada $G \mathbf{o}_{k} C_{m}$ adalah $S^{*}=\left\{v_{n_{1} 01}, v_{n_{2} 01}, \ldots, v_{n_{\gamma(G)}} 01\right\}$. Berdasarkan Teorema 2.3

$B_{i t}=\left\{v_{i 01}, v_{i t 5}, \ldots, v_{i t 4(k-1)+1}, \ldots, v_{i t}\left[4\left(\left[\frac{m}{4}\right]-1\right)+1\right] \mid k \leq\left[\frac{m}{4}\right]\right\}, \quad$ dengan $\quad i=1,2, \ldots, n$ merupakan basis ketetanggaan lokal graf $C_{m}^{i t}$. Terdapat empat kemungkinan nilai $m$ yaitu $m=4 k, m=4 k+1, m=4 k+2$, atau $m=4 k+3$.

a. Untuk $m=4 k$ atau $m=4 k+3$. Dipilih $W=\bigcup_{i=1}^{n k} B_{i t}$. Diambil sepasang titik bertetangga $x, y \in V\left(G \mathbf{o}_{\boldsymbol{k}} C_{m}\right)-W$, akibatnya $x, y \in C_{m}^{i t}-B_{i t}$. Karena $I \subseteq W$ maka berdasarkan Teorema 2.2, $W$ merupakan himpunan pembeda ketetanggaan lokal. Karena $B_{i t}$ merupakan basis ketetanggaan lokal dari $C_{m}$, maka $W$ merupakan basis ketetanggaan lokal dari graf $G \mathbf{o}_{\boldsymbol{k}} C_{m}$.

b. Sedangkan untuk $m=4 k+1$ atau $m=4 k+2$. Misalkan $W=S^{*} \bigcup_{i=1}^{n k}\left\{v_{i t 4(r-1)}\right\}$ dengan $r=2,3, \ldots,\left\lceil\frac{m}{4}\right\rceil$. Diambil sepasang titik bertetangga $x, y \in V\left(G \mathbf{o}_{\boldsymbol{k}} C_{m}\right)-W$, terdapat dua kasus yaitu $x, y \in I-S^{*}$ atau $x \in I-S^{*}$ dan $y \in C_{m}^{i t}-\left\{v_{i t 4(k-1)}\right\}$.

(i) Untuk $x, y \in I-S^{*}, x=v_{r 01}$ dan $y=v_{k 01}$ dengan $r, k \neq n_{i}, i=1,2, \ldots, \gamma(G)$. Dipilih $v_{i 01} \in I$ dengan $d\left(v_{i 01}, v_{r 01}\right)=1$ atau $d\left(v_{i 01}, v_{k 01}\right)>1$. Oleh karena itu $\left|N\left(v_{i 01}\right) \cap\left\{v_{r 01}, v_{k 01}\right\}\right|=\left|\left\{v_{r 01}\right\}\right|=1$.

(ii) Untuk $x \in I-S^{*}$ dan $y \in C_{m}^{i t}-\left\{v_{i t 4(k-1)}\right\}$, akibatnya $x=v_{r 01}$ dan $y=v_{r t 2}$ dengan $r \neq n_{i}, i=1,2, \ldots, \gamma(G)$. Karena $S^{*}$ merupakan himpunan dominasi dari induk, maka terdapat $v_{n_{k} 01} \in S^{*}$. Karena $d\left(v_{r 01}, v_{n_{k} 01}\right)=1$ dan $d\left(v_{r t 2}, v_{n_{k} 01}\right)>1$ maka $\left|N\left(v_{n_{k} 01}\right) \cap\left\{v_{r 01}, v_{r t 2}\right\}\right|=\left|\left\{v_{r 01}\right\}\right|=1$.

Berdasarkan uraian diatas maka $W$ merupakan himpunan pembeda ketetanggaan lokal. Selanjutnya akan ditunjukkan bahwa $W$ merupakan basis ketetanggaan lokal minimal. Diambil sebarang $W^{\prime} \subseteq V\left(G \mathbf{o}_{\boldsymbol{k}} C_{m}\right),\left|W^{\prime}\right|<|W|$. Terdapat empat kemungkinan nilai $m$ yaitu $m=4 k, m=4 k+1, m=4 k+2$, atau $m=4 k+3$.

a. Untuk $m=4 k$ atau $m=4 k+3$. Karena $\left|W^{\prime}\right|<|W|$ dan $\left|W^{\prime}\right|<\left|\bigcup_{i=1}^{n k} B_{i t}\right|$, akibatnya terdapat $C_{m}^{i t}$ sehingga maksimal terdapat $\left|B_{i t}\right|-1$ titik yang menjadi anggota $W^{\prime}$. Tanpa mengurangi keumuman bukti, misalkan $i=1$ dan $t=1$ sehingga maksimal terdapat $\left(\left|B_{11}\right|-1\right)$ titik yang menjadi anggota $W^{\prime}$. Akibatnya $v_{1 t r}, v_{1 \text { th }} \in$ $W^{\prime}, r \neq h$, dan $l\left(v_{1 t r}-v_{1 t h}\right)>4$. Berdasarkan Lema 2.1, $W^{\prime}$ bukan merupakan himpunan pembeda ketetanggaan lokal.

b. Sedangkan untuk $m=4 k+1$ atau $m=4 k+2$. Terdapat dua kemungkinan yaitu $W^{\prime}=I^{\prime} \bigcup_{i=1}^{n k} H^{\prime}$ dengan $I^{\prime} \subseteq I,\left|I^{\prime}\right|<\gamma(G)$, dan $\left|H^{\prime}\right|=\left|\bigcup_{i=1}^{n k}\left\{v_{i 4(r-1)}\right\}\right|$ dengan $r=$ 
$2,3, \ldots,\left\lceil\frac{m}{4}\right\rceil$ atau $W^{\prime}=I^{\prime} \bigcup_{i=1}^{n k} H^{\prime}$ dengan $\left|I^{\prime}\right|=\gamma(G), H^{\prime} \subseteq \bigcup_{i=1}^{n k} C_{m}^{i t}$, dan $\left|H^{\prime}\right|<$ $\left|\bigcup_{i=1}^{n k}\left\{v_{i 4(r-1)}\right\}\right|$.

i. Untuk $W^{\prime}=I^{\prime} \bigcup_{i=1}^{n k} H^{\prime}$ dengan $I^{\prime} \subseteq I,\left|I^{\prime}\right|<\gamma(G)$, dan $\left|H^{\prime}\right|=\left|\bigcup_{i=1}^{n k}\left\{v_{i 4(r-1)}\right\}\right|$ dengan $r=2,3, \ldots,\left\lceil\frac{m}{4}\right\rceil$. Karena $I^{\prime}$ bukan merupakan himpunan dominasi minimal, maka terdapat titik $v_{h 01} \in I-I^{\prime}$ sehingga $d\left(v_{h 01}, v_{n_{k} 01}\right)>$ $1, v_{n_{k} 01} \in I^{\prime}$. Terdapat pasangan titik bertetangga $\left(v_{h t p}, v_{h t q}\right) \in V\left(G \mathbf{o} C_{m}\right)-$ $W^{\prime}$ dengan $p \neq q$. Diambil sebarang $x \in W^{\prime}$, maka terdapat dua kemungkinan yaitu $x=v_{n_{k} 01}, v_{n_{k 0} 1} \in I^{\prime}$ atau $x=v_{i t y}$ dengan $y \neq 1, v_{i y} \in H^{\prime}$. Jika $x=$ $v_{n_{k} 01}$ maka $v_{h t p}, v_{h t q} \notin N(x)$. Sedangkan jika $x=v_{v_{i t y}}$ maka $v_{h t p}, v_{h t q} \notin$ $N(x)$. Akibatnya $\left|\left\{v_{h t p}, v_{h t q}\right\} \cap N(x)\right| \neq 1$

ii. Selanjutnya untuk $W^{\prime}=I^{\prime} \bigcup_{i=1}^{n} H^{\prime}$ dengan $\left|I^{\prime}\right|=\gamma(G), H^{\prime} \subseteq \bigcup_{i=1}^{n k} C_{m}^{i t}$, dan $\left|H^{\prime}\right|<\left|\bigcup_{i=1}^{n k}\left\{v_{i 4(r-1)}\right\}\right|$ dengan $r=2,3, \ldots,\left\lceil\frac{m}{4}\right\rceil$. Terdapat $C_{m}^{i t}$ sehingga maksimal terdapat $\left|\left\{v_{i 4(r-1)}\right\}\right|-1$ titik yang menjadi anggota $W^{\prime}$. Tanpa mengurangi keumuman bukti, misalkan $i=1$ sehingga maksimal terdapat $\left(\left|v_{14(r-1)}\right|-1\right)$ titik yang menjadi anggota $W^{\prime}$. Akibatnya terdapat pasangan titik bertetangga $v_{1 t p}, v_{1 t q} \in W^{\prime}$ dengan $p \neq q$ dan $l\left(v_{1 t p}-v_{1 t q}\right)>4$. Berdasarkan Lema 2.1, $W^{\prime}$ bukan himpunan pembeda ketetanggaan lokal.

Berdasarkan uraian diatas $W^{\prime}$ bukan himpunan pembeda ketetanggaan lokal. Oleh karena itu $W$ merupakan basis ketetanggaan lokal dan $\operatorname{dim}_{A L}\left(G \mathbf{o}_{\boldsymbol{k}} C_{m}\right)=$ $\left\{k|V(G)|\left(\operatorname{dim}_{A L}\left(C_{m}\right)-1\right)+V(G)\right.$, untuk $m=4 k$ antau $m=4 k+3$

$k|V(G)|\left(\operatorname{dim}_{A L}\left(C_{m}\right)-1\right)+\gamma(G)$, untuk $m$ yang lain

\section{Daftar Pustaka}

[1] Iswadi, H., Baskoro, E.T., Simanjutak, R., 2011, On The Metric Dimension of Corona Product Graphs, Far East Journal of Mathematical Sciences (FJMS), 52 (2): 155-170.

[2] Okamoto, F., Crosse, L., Phinezy, B., Zhang, P., dan Kalamazo, 2010, The Local Metrik Dimension of Graph, Mathematica Bohemica, 135(3): 239-255.

[3] Jannesari, M. dan Omoomi, B., 2012, The Metrik Dimension of The Lexicographic Product of Graphs, Discrete Mathematics, Vol. 312, No. 22, pp. 3349-3356.

[4] Rodriguez-Velazquez, Gomez. C.G., dan Barragan -Ramirez, G. A., 2014, Computing the Local Metric Dimension of Graph from The Local Metric Dimension of Primary Subgraph, arvix: 1402.0177v1[math.CO], 2 Februari 2014.

[5] Rodriguez-Velazquez, J. A. dan Fernau, H., 2016, On the (Adjacency) Metrik Dimension of Corona and Strong Product Graphs and Their Local Variants: Combinatorial and Computational Results. 
[6] Susilowati, L., Salamin, Utoyo, M. I. dan Estuningsih, N., 2016, The Similarity of Metric Dimension and Local Metric Dimension of Rooted Product Graph, Far East Journal of Mathematical Sciences (FJMS), Volume 97, Number 7, Pages 841-856.

[7] Saputro, S. W., Mardina, N., dan Purwasi, LA., 2013, The Metrik Dimension of Comb Product Graph, Graph Theory Conferience in Honor of Egawa's $60^{\text {th }}$ Birthday.

[8] Susilowati, L. dan Utoyo, M. I., 2016, On Comutative Characterization of Generalized Comb and Corona Products of Graph with Respect to the Local Metric Dimension, Far East Journal of Mathematical Sciences (FJMS), Volume 100.

[9] Munawwaroh, Ana Zahrotul, 2016, Dimensi Metrik Fraksional Generalisasi Hasil Kali Comb dari Graf Lengkap, Repository Unair. 